\title{
Spinal cord compression in beta-thalassemia: case report and review of the literature
}

\author{
SA Salehi*,1, T Koski ${ }^{1}$ and SL Ondra ${ }^{1}$ \\ ${ }^{1}$ Department of Neurological Surgery, The Feinberg School of Medicine, Northwestern University, Chicago, \\ Illinois, USA
}

Study design: A case report of thoracic spinal cord compression in a 34-year-old male with beta-thalassemia is reported.

Objectives: In patients with thalassemia, neurologic complaints should lead to a high index of suspicion for spinal cord compression from marrow expansion, ectopic bone formation and resultant stenosis. Initial presentation, diagnosis, radiographic findings, surgical treatment and follow-up are reviewed.

Setting: This case is reported from Chicago, Illinois.

Method: A chart review is performed for the purposes of this case report.

Results: Patient underwent decompressive laminectomy with good surgical outcome.

Conclusion: Rapid diagnosis and treatment of such a condition is essential to optimize the chances of recovery.

Spinal Cord (2004) 42, 117-123. doi:10.1038/sj.sc.3101544

Keywords: compression; hematopoiesis; thalassemia

\section{Introduction}

Thalassemia is a hematological disorder in which the red blood cells (RBCs) are formed and destroyed secondary to a defect in the proper synthesis of the globin moiety of hemoglobin. People of Mediterranean descent are at particular risk for such a condition. There is a broad range of symptom complexes in patients with thalassemia. The risk of neurologic compromise in this disease is in part due to the fact that extramedullary hematopoiesis within the spinal canal can result in the compression of neural structures. ${ }^{1}$ There have only been a few reports in the literature describing spinal cord compression by such a disease process. ${ }^{1-37}$ We present a case of a patient with thalassemia with thoracic cord compression and progressive myelopathy. The clinical syndrome, radiographic findings, pathophysiology and treatment are reviewed.

\section{Case report}

A 34-year-old male of Greek descent presented with a 12-month history of pain in the mid-thoracic region, paresthesia in his feet, progressive difficulty with ambulation and increased frequency of urination with urgency. In the 5 days prior to evaluation, he developed

*Correspondence: SA Salehi, 233 E. Erie Street, Suite 614, Chicago, IL 60611, USA severe weakness in his lower extremities resulting in the ability to ambulate only with assistance. His difficulty with ambulation marginally improved after a blood transfusion. His hemoglobin count was found to be $7.1 \mathrm{~g} / \mathrm{dl}$ at the time of his presentation.

Physical examination demonstrated a young male, awake and oriented to person, place and time. His cranial nerve examinations 2-12 were normal. His motor strength in all extremities was $5 / 5$. On sensory testing, he had decreased sensation to pinprick and proprioception in the lower extremities. Reflexes disclosed lower extremity reflex disinhibition, a Babinski response and clonus bilaterally. Rectal tone was normal. His gait was spastic.

MRI of the neuro axis demonstrated severe spinal cord compression from $\mathrm{T} 2$ to $\mathrm{T} 11$ due to an extramedullary mass, which arose posterior to the cord in the posterior elements of the thoracic vertebrae and epidural space. The signal intensity within the cord also demonstrated early changes consistent with myelomalacia (Figure 1a-c). He also had nerve root compression by the same disease process in the lumbar-sacral junction.

The patient was admitted for medical evaluation and stabilization, and he was started on steroids (dexamethasone). The patient also underwent a transfusion to raise his hemoglobin from 7.1 to $9.8 \mathrm{~g} / \mathrm{dl}$ to maintain cord perfusion during the anticipated surgery blood loss. 

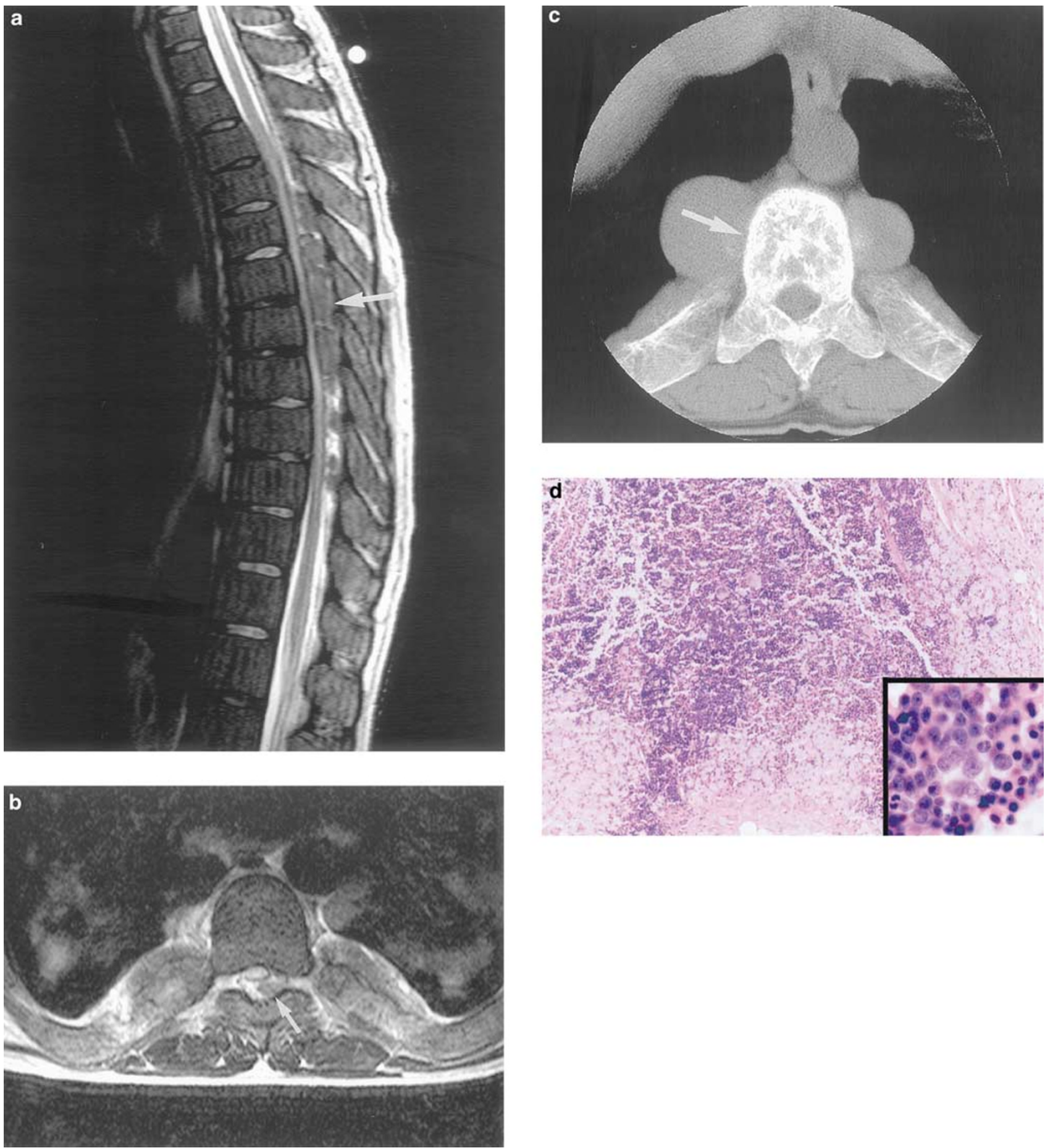

Figure 1 (a) Sagittal MRI of the thoracic spine showing the spinal cord compression (white arrow). (b) Axial MRI of the midthoracic level demonstrating the amount of cord displacement by the extramedullary mass (white arrow). (c) Axial CT of the midthoracic spine region. Note the overgrowth of the marrow in response to anemia as a compensatory mechanism (white arrow). (d) Pathology slide of the bone marrow in the lamina of the thoracic spine showing fibroadipose tissue, extramedullary hematopoiesis with erythroid hyperplasia. The inset shows the deposits of foamy histiocytes

This elevation in hemoglobin again resulted in a subjective improvement of his motor strength. The patient had multiple blood antibodies from prior transfusions. This required several days to crossmatch blood for the surgery.
A thoracic laminectomy to decompress the spinal canal was planned. As the decompression was limited to the thoracic spine and spared the cervical and lumbar junctions, stabilization was not felt to be necessary. The patient was placed in a prone position and the mean 
arterial blood pressure was maintained at $90 \mathrm{mmHg}$ or greater by volume expansion to maintain spinal cord perfusion. He was also placed on methylprednisolone protocol, normally used for acute spinal cord injury, intraoperatively. The patient did not require any intraoperative vasopressors to keep the mean blood pressure elevated. A standard thoracic laminectomy was performed from T2 to T11 with a high speed drill.

The laminae were grossly thickened due to the expansion of the cancellous portion of the bone. After the laminectomy, a thinned yellow ligament was removed. The epidural fat was found to be replaced by ectopic hematopoietic tissue resembling cancellous bone. This maintained spinal cord compression post laminectomy and was removed with a Kerrison punch. Hemostasis was achieved with a bipolar cautery. All posterior elements and nerve root exit zones were thoroughly decompressed. Care was taken not to injure the facets or joint capsules. After the decompression, the dura was pulsatile. Gelfoam was placed for hemostasis and two large Jackson-Pratt drains were left in the wound to prevent cord compression secondary to epidural blood accumulation.

The final pathological diagnosis showed markedly hypercellular bone marrow with marked erythroid hyperplasia. This was associated with deposits of sheets of foamy cells without associated bony sclerosis. The epidural mass was composed of soft tissue with extramedullary hematopoiesis featuring the same characteristics mentioned above. The overall histomorphology was that of hyperplastic bone marrow with erythroid hyperplasia associated with deposits of foamy histiocytes, which was also occurring in adjacent soft tissue in the form of extramedullary hematopoiesis (Figure 1d).

Postoperatively, the patient underwent a 7-day steroid taper. He received 2 additional units of packed red blood cells in the postoperative period. He was mobilized 1 day following surgery. His major postoperative complaint related to ileus and incisional pain. He had full motor strength in all his extremities and a remarkably improved gait. No change in bladder function was noted. The postoperative MRI showed complete decompression of the spinal cord (Figure 2a, b).

On 3 months follow-up, the patient improved compared to his preoperative status. He could ambulate independently, had no difficulty with urination, had normal strength and did not require narcotics for pain relief.

\section{Discussion}

Gatto $^{37}$ was the first to describe spinal cord compression from the extramedullary overgrowth of the hematopoietic tissue. The diagnosis at that time was based on clinical examination and myelography. At present, with the addition of CT and MRI, the physician's repertoire for diagnosis is much improved. Characteristic findings
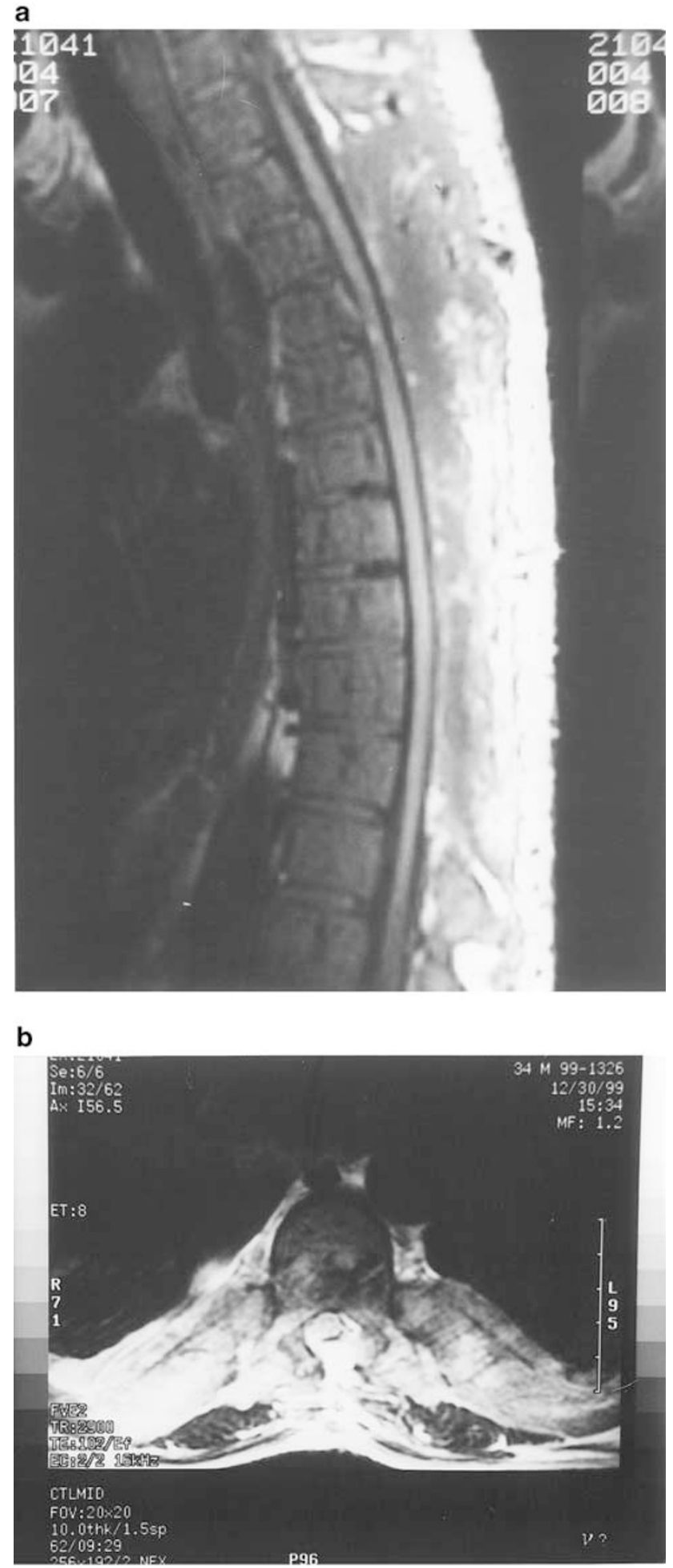

Figure 2 (a) Postoperative MRI of the thoracic spine. Observe the resolution of the cord compression. (b) The axial MRI of the mid-thoracic spine showing the resolution of the cord compression

of thickened lamina, extramedullary marrow tissue and cord compression are easily identified. In the 12 thalassemic patients studied by Issargisil et al, ${ }^{1}$ the 
male-to-female ratio for spinal cord compression by extramedullary mass was 5:1. Thoracic cord compression was seen primarily in the lower thoracic spine.

Extramedullary hematopoiesis occurs in multiple blood disorders. The usual organ involvement includes the liver, spleen, bone marrow and lymph nodes. The onset of neurologic symptoms in a patient with such underlying blood dyscrasias should prompt a high clinical suspicion for cord compression or thecal sac compression by an extramedullary hematopoietic process.

The treatment modalities available to such patients are limited. Intervention options have included multiple blood transfusions to downregulate erythropoietin production, radiation therapy to halt the production of overgrown marrow tissue, surgical decompression or a combination of any of the above. ${ }^{1,26}$ The relative benefit of one treatment over another has not been clearly established due to the infrequency of this disorder.

The risks of surgical treatment include excessive bleeding in a patient with a low hemoglobin and difficulty in transfusion due to antibodies and cardio pulmonary stress. The benefit of surgery includes immediate resolution of compression and its symptoms upon decompression. Surgical decompression also provides a good histologic diagnosis. Lau et $a l^{26}$ report the case of a 28-year-old woman with cord compression in the thoracic spine who underwent surgical decompression with immediate postoperative recovery of weakness. A complete resolution of symptoms had occurred at 2 months follow-up. Multiple transfusions were also required to maintain the hemoglobin above $10 \mathrm{~g} / \mathrm{dl}$.

The role of transfusion is typically an adjunctive therapy while waiting for a more definitive treatment. It is used in the perioperative period to maintain perfusion. ${ }^{1,13}$ Parsa and Oriezy ${ }^{30}$ argues that transfusion therapy can be used as a diagnostic tool and the sole treatment modality for patients with thalassemia. They describe the case of a patient who was treated for cord compression with a 4-year follow-up with no need for further therapy. The major risk of transfusion is the inherent risk of infectious disease transfer, iron overload, formation of antibodies and other such problems.
We believe that transfusion is a poor primary treatment as it is increasingly unrealistic and difficult to transfuse patients. As such, it is our opinion that transfusion can be used only as an adjunctive treatment modality.

The risks of radiotherapy in the treatment of cord compression in such patients include the lack of any tissue for histologic diagnosis and the risks involved with radiation exposure. The benefits include ready availability, effectiveness in the resolution of symptoms in a short period of time and reduction of local recurrence. ${ }^{17}$ Abassioun and Amir-Jamshidi ${ }^{8}$ in 1982 reported the case of a 15-year-old female who was paraparetic with long tract signs. The patient's symptoms resolved after 1500 cGy of radiation in five treatments with only residual right sustained clonus. Kaufman et $a l^{17}$ also reported two patients with thalassemia who underwent radiation therapy with resolution of symptoms in 3-7 days. Singhal et $a l^{21}$ in a review of the literature argue that radiation therapy should be the primary modality for treatment, and surgical intervention and transfusion should be reserved for the recurrent cases postradiation. The radiation dosage used mostly in different treatment protocols included a range between 1000 and $3000 \mathrm{cGy}$.

Cross et $a l^{36}{ }^{36}$ Luyendijk et $a l^{5}$ and Shin et $a l^{27}$ each report patients with cord compression who underwent combined surgical decompression and radiation therapy with good results. In each of these studies, it has been argued that local recurrence may be decreased using radiation therapy to accompany spinal decompression.

Our patient demonstrated only partial response to transfusion. The spinal cord had evidence of injury and myelomalacia on MRI. Given advanced and progressive findings and active progression, we do not believe that transfusion alone was a realistic treatment option. Radiation exposes an already damaged cord to further potential injury. As such, we feel that such cases are best treated by a surgical decompression. Radiation can be saved as a salvage procedure after a wound is healed if the patient has residual or recurrent disease.

A thorough medical search of the Medline describing different hemoglobinopathies and their spinal cord consequences is summarized in Table 1.

Table 1 Different hemoglobinopathies and their spinal cord consequences

\begin{tabular}{|c|c|c|c|c|c|c|c|c|}
\hline Ref. & Year & Study & $\begin{array}{c}\text { Age } \\
\text { (years) }\end{array}$ & Sex & Diagnosis & Presentation & Treatment & Outcome \\
\hline 5 & 1975 & Luyendijk et al & 42 & M & Thalassemia & Paraparesis & Surgery/XRT & Partial recovery \\
\hline 2 & 1978 & $\begin{array}{l}\text { Cromwell and } \\
\text { Kerber }\end{array}$ & 36 & M & $\begin{array}{l}\text { Angiogenic myeloid } \\
\text { metaplasia }\end{array}$ & Paraparesis & $\begin{array}{l}\mathrm{XRT} / \text { steroids } \\
\text { exchange }\end{array}$ & Partial recovery \\
\hline 3 & 1979 & Stahl et al & 54 & M & Myeloid metaplasia & Paraparesis & Transfusions & Death \\
\hline 4 & 1980 & Rice et al & 68 & M & Polycythemia vera & Paraplegia & $\begin{array}{l}\text { Surgery/XRT/ } \\
\text { steroids }\end{array}$ & No recovery \\
\hline \multirow[t]{4}{*}{5} & 1980 & Issargisil et al & 24 & M & Thalassemia & Paraparesis & Transfusions & Partial recovery \\
\hline & 1980 & Issargisil et al & 22 & M & Thalassemia & Paraparesis & XRT & Partial recovery \\
\hline & 1980 & Issargisil et al & 34 & M & Thalassemia & Paraparesis & XRT/steroids & Partial recovery \\
\hline & 1980 & Issargisil et al & 37 & M & Thalassemia & Paraparesis & Transfusions & Partial recovery \\
\hline
\end{tabular}


Table 1 (continued)

\begin{tabular}{|c|c|c|c|c|c|c|c|c|}
\hline Ref. & Year & Study & $\begin{array}{c}\text { Age } \\
\text { (years) }\end{array}$ & Sex & Diagnosis & Presentation & Treatment & Outcome \\
\hline & 1980 & Issargisil et al & 19 & $\mathrm{~F}$ & Thalassemia & Paraparesis & XRT & Partial recovery \\
\hline & 1980 & Issargisil et al & 32 & M & Thalassemia & Paraparesis & XRT & Partial recovery \\
\hline & 1980 & Issargisil et al & 25 & $\mathrm{~F}$ & Thalassemia & Paraparesis & XRT & Partial recovery \\
\hline & 1980 & Issargisil et al & 26 & M & Thalassemia & Paraparesis & XRT & Partial recovery \\
\hline & 1980 & Issargisil et al & 40 & M & Thalassemia & Paraparesis & XRT & Partial recovery \\
\hline & 1980 & Issargisil et al & 17 & M & Thalassemia & Paraparesis & $\mathrm{XRT} /$ transfusions & Partial recovery \\
\hline & 1980 & Issargisil et al & 29 & M & Thalassemia & Paraparesis & Surgery/XRT & Partial recovery \\
\hline & 1980 & Issargisil et al & 23 & M & Thalassemia & Paraparesis & $\mathrm{XRT} /$ transfusions & Partial recovery \\
\hline 6 & 1980 & Oustwani et al & 70 & M & Polycythemia & Paraplegia & Surgery & No recovery \\
\hline 7 & 1981 & Ahmed et al & 17 & M & Thalassemia & Paraparesis & Surgery & Partial recovery \\
\hline \multirow[t]{2}{*}{8} & 1982 & $\begin{array}{l}\text { Abassioun and } \\
\text { Amir-jamshidi }\end{array}$ & 19 & M & Thalassemia & Paraparesis & Surgery & Full recovery \\
\hline & 1982 & $\begin{array}{l}\text { Abassioun and } \\
\text { Amir-jamshidi }\end{array}$ & 19 & M & Thalassemia & Paraparesis & Surgery & Partial recovery \\
\hline 9 & 1982 & Luitjes et al & 55 & M & Thalassemia & Paraparesis & Surgery/XRT & Partial recovery \\
\hline 10 & 1982 & Heffez et al & 72 & M & Thalassemia & Paraparesis & Surgery/XRT & $\begin{array}{l}\text { Partial recovery - } \\
\text { unrelated death. }\end{array}$ \\
\hline 11 & 1984 & Lewkow and Shah & 43 & M & Sickle cell anemia & Paraplegia & $\begin{array}{l}\text { Surgery/XRT / } \\
\text { transfusions }\end{array}$ & No recovery \\
\hline 12 & 1985 & Price and Bell & 74 & $\mathrm{~F}$ & Myelofibrosis & Back pain & Surgery/XRT & Full recovery \\
\hline 13 & 1987 & Mann et al & 21 & M & Thalassemia & Paraparesis & Surgery & Full recovery \\
\hline 14 & 1988 & Jackson et al & 29 & M & Thalassemia & Paraparesis & XRT & Full recovery \\
\hline 15 & 1989 & Jackson and Burton & 52 & M & Polycythemia vera & Paraplegia & XRT & Partial recovery \\
\hline \multirow[t]{5}{*}{16} & 1990 & Papavasiliou et al & 22 & M & Thalassemia & Paraparesis & XRT & Partial recovery \\
\hline & 1990 & Papavasiliou et al & 26 & M & Thalassemia & Paraparesis & XRT & Partial recovery \\
\hline & 1990 & Papavasiliou et al & 34 & M & Sickle cell anemia & Back pain & XRT & Full recovery \\
\hline & 1990 & Papavasiliou et al & 24 & M & Thalassemia & Paraparesis & XRT & Full recovery \\
\hline & 1990 & Papavasiliou et al & 32 & $\mathrm{~F}$ & $\begin{array}{l}\text { Thalassemia/ } \\
\text { pregnancy }\end{array}$ & Paraparesis & No therapy & No outcome listed \\
\hline \multirow[t]{2}{*}{17} & 1991 & Kaufman et al & 41 & $\mathrm{~F}$ & Thalassemia & Paraparesis & XRT & Partial recovery \\
\hline & & Kaufman et al & 40 & $\mathrm{~F}$ & Thalassemia & Paraparesis & XRT/steroids & Partial recovery \\
\hline 18 & 1991 & Singounas et al & 32 & $\mathrm{~F}$ & Thalassemia & Paraparesis & Transfusions & Full recovery \\
\hline 19 & 1991 & Hassoun et al & 22 & M & Thalassemia & Paraparesis & XRT & Full recovery \\
\hline \multirow[t]{2}{*}{20} & 1991 & Amir-jamshidi et al & 16 & M & Thalassemia & Paraparesis & Surgery & Full recovery \\
\hline & 1991 & Amir-jamshidi et al & 14 & M & Thalassemia & Paraparesis & Surgery & Full recovery \\
\hline \multirow[t]{2}{*}{21} & 1991 & Singhal et al & 21 & M & Thalassemia & Paraparesis & Surgery/XRT & Partial recovery \\
\hline & 1991 & Singhal et al & 33 & M & Thalassemia & Paraparesis & XRT & Partial recovery \\
\hline 22 & 1992 & $\begin{array}{l}\text { Pantongrag-Brown } \\
\text { and Suwanwela }\end{array}$ & 27 & M & Thalassemia & Paraparesis & XRT & Partial recovery \\
\hline 23 & 1993 & McDonald et al & 67 & M & Myelofibrosis & Paraparesis & XRT & Partial recovery \\
\hline 24 & 1993 & De Klippel et al & 61 & M & Myelofibrosis & Paraparesis & $\begin{array}{l}\text { Surgery/XRT/ } \\
\text { steroids }\end{array}$ & $\begin{array}{l}\text { Full recovery- } \\
\text { unrelated death }\end{array}$ \\
\hline \multirow[t]{2}{*}{25} & 1993 & Dore et al & 30 & M & Thalassemia & Paraparesis & XRT & Partial recovery \\
\hline & 1993 & Dore et al & 39 & M & Thalassemia & Paraparesis & XRT & Partial recovery \\
\hline 26 & 1994 & Lau et al & 28 & $\mathrm{~F}$ & Cooley's anemia & Paraparesis & Surgery & Full recovery \\
\hline 27 & 1994 & Shin et al & 22 & M & Thalassemia & Myelopathy & Surgery/XRT & Full recovery \\
\hline 28 & 1994 & Cook and Sharp & 67 & M & Myelofibrosis & Paraparesis & Surgery/XRT & Partial recovery \\
\hline 29 & 1995 & Gouliamos et al & 20 & M & Thalassemia & Back pain & XRT & Full recovery \\
\hline \multirow[t]{2}{*}{30} & 1995 & Parsa and Oriezy & 16 & $\mathrm{~F}$ & Thalassemia & Paraparesis & $\mathrm{XRT} /$ transfusions & Partial recovery \\
\hline & 1995 & Parsa and Oriezy & 39 & M & Thalassemia & Paraparesis & Transfusions & Partial recovery \\
\hline 31 & 1996 & de Morais et al & 46 & M & $\begin{array}{l}\text { Polycythemia } \\
\text { vera }\end{array}$ & Paraplegia & $\begin{array}{l}\text { Surgery/ } \\
\text { phlebotomy }\end{array}$ & $\begin{array}{l}\text { No recovery- } \\
\text { unrelated death }\end{array}$ \\
\hline 32 & 1997 & Guermazi et al & 36 & M & Myelofibrosis & Paraparesis & XRT/steroids & Partial recovery \\
\hline 33 & 1997 & Aydingoz et al & 27 & M & Thalassemia & Paraparesis & XRT & Partial recovery \\
\hline 34 & 1998 & Munn et al & 35 & M & Thalassemia & Paraparesis & XRT & Partial recovery \\
\hline 35 & 2001 & Haran and $\mathrm{Ni}$ & 68 & M & $\begin{array}{l}\text { Polycythemia } \\
\text { vera }\end{array}$ & Paraparesis & XRT & Partial recovery \\
\hline
\end{tabular}




\section{Conclusion}

Extramedullary erythropoiesis is a natural tissue response to a low hemoglobin count in patients with thalassemia. This may cause neurologic conditions such as spinal cord compression. Rapid diagnosis and treatment is important to prevent further neurological injury and improve functional outcome in such patients. Surgical decompression and radiation therapy are both effective in treating the compression. Transfusion can also transiently ameliorate the symptoms.

Given the infrequency of the disease and rare symptomatic cord compression, it is unlikely that a randomization of radiation versus surgical treatment could be carried out in an individual institution. This requires a multi-center randomized study. By reviewing the literature, we conclude that in patients with early spinal cord compression, radiation or surgery can be equally effective. However, we prefer immediate decompression with radiation as a salvage in younger patients with signal changes within their cord to reduce the longterm effects of radiation on the neural tissues.

\section{References}

1 Issargisil S, Piankijagum A, Prawase W. Spinal cord compression in thalassemia. Report of 12 cases and recommendations for treatment. Arch Intern Med 1981; 141: 1033-1036.

2 Cromwell LD, Kerber C. Spinal cord compression by extramedullary hematopoiesis in myeloid metaplasia. Radiology 1978; 128: 118.

3 Stahl SM, Ellinger G, Baringer JR. Progressive myelopathy due to extramedullary hematopoiesis: case report and review of the literature. Ann Neurol 1979; 5: 485-489.

4 Rice GP, Assis LJ, Barr RM, Ebers GC. Extramedullary hematopoiesis and spinal cord compression complicating polycythemia rubra vera. Ann Neurol 1980; 7: 81-84.

5 Luyendijk W, Went L, Schaad HD. Spinal cord compression due to extramedullary hematopoiesis in homozygous thalassemia. Case report. J Neurosurg 1975; 42: 212-216.

6 Oustwani MB, Kurtides ES, Christ M, Ciric I. Spinal cord compression with paraplegia in myelofibrosis. Arch Neurol 1980; 37: 81-84.

7 Ahmed F, Tobin MS, Cohen DF, Gomez-Leon G. Beta Thalassemia. Spinal cord compression. NY State J Med 1981; 81: 1505-1508.

8 Abassioun K, Amir-Jamshidi A. Curable paraplegia due to extradural hematopoietic tissue in thalassemia. Neurosurgery 1982; 11: 804-807.

9 Luitjes WF, Braakman R, Abels J. Spinal cord compression in a new homozygous variant of beta-thalassemia. J Neurosurg 1982; 57: 846-848.

10 Heffez DS, Sawaya R, Udvarhelyi GB, Mann R. Spinal epidural extramedullary hematopoiesis with cord compression in a patient with refractory sideroblastic anemia. Case report. J Neurosurg 1982; 57: 399-406.

11 Lewkow LM, Shah I. Sickle cell anemia and epidural extramedullary hematopoiesis. Am J Med 1984; 76: 748-751.

12 Price F, Bell H. Spinal cord compression due to extramedullary hematopoiesis. Successful treatment in a patient with longstanding myelofibrosis. JAMA 1985; 253: 2876-2877.

13 Mann KS et al. Paraplegia due to extramedullary hematopoiesis in thalassemia. Case report. J Neurosurg 1987; 66: 938-940.

14 Jackson Jr DV, Randall ME, Richards F. Spinal cord compression due to extramedullary hematopoiesis in thalassemia: long term follow-up after radiotherapy. Surg Neurol 1988; 29: 389-392.

15 Jackson A, Burton IE. Retroperitoneal mass and spinal cord compression due to extramedullary haemopoiesis in polycythemia rubra vera. Br J Radial 1990; 42: 91-92.

16 Papavasiliou C et al. CT and MRI of symptomatic spinal involvement by extramedullary hematopoiesis. Clin Radiol 1990; 42: 91-92.

17 Kaufman T, Coleman M, Giardina P, Nisce LZ. The role of radiation therapy in management of hematopoietic neurologic complications in thalassemia. Acta Haematol 1991; 85: 156-159.

18 Singounas EG et al. Paraplegia in a pregnant thalassemic woman due to extramedullary hematopoiesis: successful management with transfusions. Surg Neurol 1991; 36: 210-215.

19 Hassoun $\mathrm{H}$ et al. Spinal cord compression secondary to extramedullary hematopoiesis: a noninvasive management based on MRI. Am J Hematol 1991; 37: 201-203.

20 Amir-jamshidi A, Abbassioun K, Ketabchi SE. Spinal extradural hematopoiesis in adolescents with thalassemia. Report of two cases and a review of the literature. Childs Nerv Syst 1991; 7: 223-225.

21 Singhal $\mathrm{S}$ et al. The role of radiation therapy in the management of spinal cord compression due to extramedullary hematopoiesis in thalassemia. J Neurol Neurosurg Psychiatry 1992; 55: 310-312.

22 Pantongrag-Brown L, Suwanwela N. Case report: chronic spinal cord compression from extramedullary haematopoiesis in thalassemia - MRI findings. Clin Radiol 1992; 46: 281-283.

23 McDonald AC, Cook G, Sharp RA, Bissett D. Spinal cord compression in myelofibrosis - a case report. Acta Oncol 1993; 32: 692-693.

24 De Klippel N et al. Progressive paraparesis due to thoracic extramedullary hematopoiesis in myelofibrosis. Case report. J Neurosurg 1993; 79: 125-127.

25 Dore F et al. Recurrence of spinal cord compression from extramedullary hematopoiesis in thalassemia intermedia treated with low doses of radiotherapy. Am J Hematol 1993; 44: 148.

26 Lau SK, Chan CK, Chow YY. Cord compression due to extramedullary haemopoiesis in a patient with thalassemia. Spine 1994; 19: 2467-2470.

27 Shin KH et al. Combined radiotherapeutic and surgical management of a spinal cord compression by extramedullary hematopoiesis in a patient with hemoglobin E betathalassemia. Acta Haematol 1994; 91: 154-157.

28 Cook G, Sharp RA. Spinal cord compression due to extramedullary haemopoiesis in myelofibrosis. $J$ Clin Pathol 1994; 47: 464-465.

29 Gouliamos AD et al. Case report: magnetic resonance imaging of spinal cord compression in thalassemia before and after radiation treatment. Clin Radiol 1995; 50: 504-505.

30 Parsa K, Oriezy A. Nonsurgical approach to paraparesis due to extramedullary hematopoiesis. Report of two cases. J Neurosurg 1995; 82: 657-660. 
31 de Morais JC et al. Spinal cord compression due to extramedullary hematopoiesis in the proliferative phase of polycythemia vera. Acta Haematol 1996; 96: 242-244.

32 Guemarazi A, Miaux Y, Chiras J. Imaging of spinal cord compression due to thoracic extramedullary hematopoiesis in myelofibrosis. Neuroradiology 1997; 39: 733-736.

33 Aydingoz U, Oto A, Cila A. Spinal cord compression due to epidural extramedullary haematopoiesis in thalassemia: MRI. Neuroradiology 1997; 39: 870-872.

34 Munn RK, Kramer CA, Arnold SM. Spinal cord compression due to extramedullary hematopoiesis in beta-thalassemia intermedia. Int J Radial Oncol Biol Phys 1998; 42: 607-609.

35 Haran M, Ni S. Recurrent reversible paraplegia. Lancet 2001; 357: 1092.

36 Cross JN, Morgan OS, Gibbs WN, Cheruvanky I. Spinal cord compression in thalassemia. J Neurol Neurosurg Psychiatry 1997; 40: 1120-1122.

37 Gatto I, Terrana V, Biondi L. Comprssione sul midollo spinale da proliferazione di midollo osseo nello spazio epidurale in soggetto affetto da malattia di Colley splenectomizzato. Haematologica 1954; 38: 61-75. 